\title{
What Do We Know About SoTL?
}

\author{
A Review of Defining and Supporting the Scholarship of Teaching and Learning (SoTL): A
} Sector-Wide Study by Joëlle Fanghanel, Jane Pritchard, Jacqueline Potter, and Gina Wisker.

This 40-page review is a must-read for everyone interested in the Scholarship of Teaching and Learning. It is, as the title implies, a sector-wide study based on a literature review on the current situation of SoTL in higher education. Although the study is primarily framed in and focused on the UK, there are influences and insights from other countries-albeit mainly Anglo-Saxon. The recognition and relevance is high even for a reader outside of the UK, at least for this Swedish reader, as the review can add to what the authors refer to as "contextualised scholarship" (p. 10). In other words, if you are an academic or a student engaged in SoTL you will find a useful big picture of SoTL in this review. Also, if you are an academic leader or a faculty developer, you will find inspiration and knowledge about SoTL in a collegial, disciplinary, and institutional context.

The authors have provided a thorough, yet easily accessible and up-to-date, snapshot of SoTL. The review contains subtitles such as "Defining SoTL," "SoTL in the Disciplines," "SoTL and Educational Development," "SoTL and Institutional Structures for Recognition and Excellence," "National and International SoTL Initiatives," and "Student Engagement with SoTL." Each section contains a multitude of previous research and literature and ends with a brief summary, which makes a quick read easy. The text concludes with a set of findings and recommendations emerging from the literature review. Depending on your own engagement in SoTL, there is something to take away for everyone.

After my reading I interpret the focus of the text not so much on the individual academic who engages with SoTL, or who wants to become engaged. There are no how-to-do-SoTL-aspects in the text. Rather, this review is valuable if you want to get a state-of-the-art-overview of the SoTL-field, and for groups of people, who are seeking ways to understand, support and embed SoTL in their disciplines and/or institutions. The authors use a model of micro- (individuals), meso- (institutions), and macro- (national and international contexts) levels to frame SoTL in the higher education system. This is helpful, as most people who are engaged in SoTL are operating at different levels and with various levels in their focus. For a reader who is completely unfamiliar with SoTL, I recommend reading section 2- "Defining SoTL"- before the introduction and background. As the authors point out: "characteristics of SoTL represent different facets of a complex object" (p. 7). Indeed.

This kind of review is very useful no matter which SoTL-context is in focus. It adds to the global understanding of SoTL as a movement. Already, since the report was published initiatives are under way in South-Africa (SoTL in the South), in Asia (SoTL-Asia), and in Europe (Euro-SoTL). As the authors so wisely highlight, "SoTL's richness is not in the model originally devised by Boyer, but in what it has become" (p. 15). This study adds to that richness. And SoTL is constantly becoming.

\section{Katarina Mårtensson is a senior lecturer and academic developer at Lund University, Sweden, and Co-President elect of ISSOTL. Her research focuses on academic microcultures, leadership, and SoTL.}

\section{REFERENCES}

Fanghanel, J., Prithard, J., Potter, J., and Wisker, G. Defining and supporting the Scholarship of Teaching and Learning (SoTL): A sector-wide study. Literature review. Higher Education Academy, 2016. 
(C) (i) Copyright for the content of articles published in Teaching \& Learning Inquiry resides with the authors, and copyright for the publication layout resides with the journal. These copyright holders have agreed that this article should be available on open access under a Creative Commons Attribution License 4.0 International (https://creativecommons.org/licenses/by/4.0). The only constraint on reproduction and distribution, and the only role for copyright in this domain, should be to give authors control over the integrity of their work and the right to be properly acknowledged and cited, and to cite Teaching \& Learning Inquiry as the original place of publication. Readers are free to share these materials - as long as appropriate credit is given, a link to the license is provided, and any changes are indicated. 